\title{
Assessment of the effectiveness of the PPD-mallein produced in Brazil for diagnosing glanders in mules
}

\author{
Karla Patrícia Chaves da Silva ${ }^{1}$, Galba Maria de Campos Takaki ${ }^{2}$, \\ Leonildo Bento Galiza da Silva ${ }^{3}$, Tomoe Noda Saukas ${ }^{3}$, \\ André Souza Santos ${ }^{3}$, Rinaldo Aparecido Mota ${ }^{3}$ \\ ${ }^{1}$ Departamento de Medicina Veterinária, Universidade Federal de Alagoas, Maceió, AL, Brazil. \\ ${ }^{2}$ Núcleo de Pesquisas em Ciências Ambientais, Universidade Católica de Pernambuco, Recife, PE, Brazil. \\ ${ }^{3}$ Departamento de Medicina Veterinária, Universidade Federal Rural de Pernambuco, Recife, PE, Brazil.
}

Submitted: November 21, 2011; Approved: July 2, 2012.

\begin{abstract}
To assess the potency of the PPD-mallein produced in Brazil, five animals were from a property identified as a focus of glanders. These animals had suggestive clinical signs of the disease and the other five, from a property free from glanders, showed no clinical signs and were serology negative (control group). PPD-mallein from Burkholderia mallei was obtained by precipitation with trichloroacetic acid and ammonium sulfate. The animals were inoculated according to the criteria established by Department of Agriculture, Livestock and Supply (MAPA) for the diagnosis of glanders. After $48 \mathrm{~h}$ of application of PPD-mallein, there was swelling in the area of application, presence of ocular secretion and tears in sick animals. The control group showed no inflammatory reaction at the site of inoculation of PPD-mallein. This immunogen produced in Brazil and still being tested was effective for identifying the infection in true positive animals and excluding the truly negative ones, being a new possibility for diagnosis and control of glanders
\end{abstract}

Key words: Mallein test, Equus asinus, diagnosis.

Glanders is a deadly bacterial disease of horses caused by Burkholderia mallei. The disease is usually chronic in horses and acute in mules (Al-Ani et al., 1998). In Brazil, the re-emergence of the disease was identified at the end of the last century through the description of clinical, microbiological and serological tests in equine animals in the coastal region from state of Pernambuco and the diagnosis of glanders in Brazil follows the criteria laid down by MAPA Normative Instruction $\mathrm{N}^{\circ} 24$ for the control and eradication of the disease (Brasil, 2004). For diagnosis, the use of the complement fixation (CF) serologic test is recommended and those animals whose sera are anticomplementary or self-react with normal antigen in CF should be tested in the maleinization, using imported, mallein there is the possibility of nonspecific reaction in serological testing because of homologous antigens between $B$. mallei and $B$. pseudomallei. This reaction can result in a falsepositive diagnosis, especially in animals imported from ar- eas where melioidosis occurs in humans. This reaction is not observed in malleinization (Hagebock et al., 1993).

Malleinization is similar to tuberculization; mallein is a glycoprotein extracted from cultures of $B$. mallei, used as antigen in Intradermal-eyelid test in horses (Verma et al., 1990, 1994; Neubauer et al., 2005). This test is based on the detection of immune cellular response and provides greater specificity in the diagnosis of glanders. Considering the possibility of contributing to the diagnosis of glanders in Brazil, a Purified Protein Derivate (PPD) mallein was produced through precipitation and acid purification for use in malleinization tests. The objective of this study was to evaluate the potency of this immunogen in mules with clinical, positive serological and bacteriological diagnoses for glanders. The article was approved by the research ethics committee (nº09909-2011-35 UFAL)

For evaluation of PPD-mallein we used ten adult mules (Equus asinus), comig from the Coastal Region in 
Pernambuco State. Five animals were from a property identified as a focus of glanders. These animals had suggestive clinical signs of the disease and the other five, from a property free from glanders, showed no clinical signs and were serology negative (control group). To confirm the diagnosis of the disease in the animals studied, the serological complement fixation technique was used, followed by the bacteriological examination. Purulent content from cutaneous animals with clinical signs were collected and sown in Petri dishes containing agar base enriched with $10 \%$ sheep blood and the plates were incubated at $37{ }^{\circ} \mathrm{C}$ for $72 \mathrm{~h}$. The bacteria were subsequently identified through biochemical oxidase tests, catalase, Voges Proskauer (VP), indol, $\mathrm{H}_{2} \mathrm{~S}$ production, motility, arginine hydrolysis, D-glucose gas, gelatin liquefaction, urease, glucose, maltose, galactose, lactose, fructose, mannose, sucrose and mannitol (Mota et $a l ., 2000$ ). During the clinical examination of sick animals, we noticed edema in the pelvic limbs and in the prepuce, lymphangitis in the neck, head and limbs, bilateral purulent nasal secretion, dyspnea, pulmonary stertors and progressive loss of weight. The clinical diagnosis was suggestive of glanders (Mota et al., 2000; Rabelo et al., 2006).

After the confirmation of infection by bacterial isolation and antibody test, we used the PPD-mallein produced experimentally in Brazil (Silva, 2010) to confirm the disease We applied $0.1 \mathrm{~mL}$ of immunogen intradermally in the lower eyelid of the right eye of each animal. To prove the effectiveness of mallein, five mules serologically and bacteriologically negative for glanders were inoculated in the same conditions. The reading was performed after $48 \mathrm{~h}$ and followed the criteria established in IN 24 (Brasil, 2004; OIE, 2010) that characterize as a positive reaction the presence of persistent edema with or without observation of ocular secretion. The five sick animals were reactive to the test and showed progressive and persistent edema, starting $24 \mathrm{~h}$ later and with a peak $48 \mathrm{~h}$ after inoculation; ocular secretion was noticed in some animals, but not in others. In the control group, neither an inflammatory reaction nor any other clinical signs in the inoculated area were noticed (Figure 1).

The PPD-mallein tested induced an inflammatory response in the sick animals, which developed an allergic reaction and exhibited Delayed-Type Hypersensibility reactions of (DTH), as seen in Figure 2. The intradermopalpebral positive reaction, besides being characterized by ocular edema can also be associated with other findings such as photosensibility, tear shedding and suppuration within $48 \mathrm{~h}$ after inoculation (Hagebock et al., 1993). These findings were also observed in positive animals in this study. The variation in the pattern of inflammatory response after inoculation of PPD-mallein in infected animals is directly related to the degree of infection in each equine. During the phases of bacteremia, when a more intense circulation of the infectious agent occurs, the antigenic stimulus is stronger, generating a greater effect of

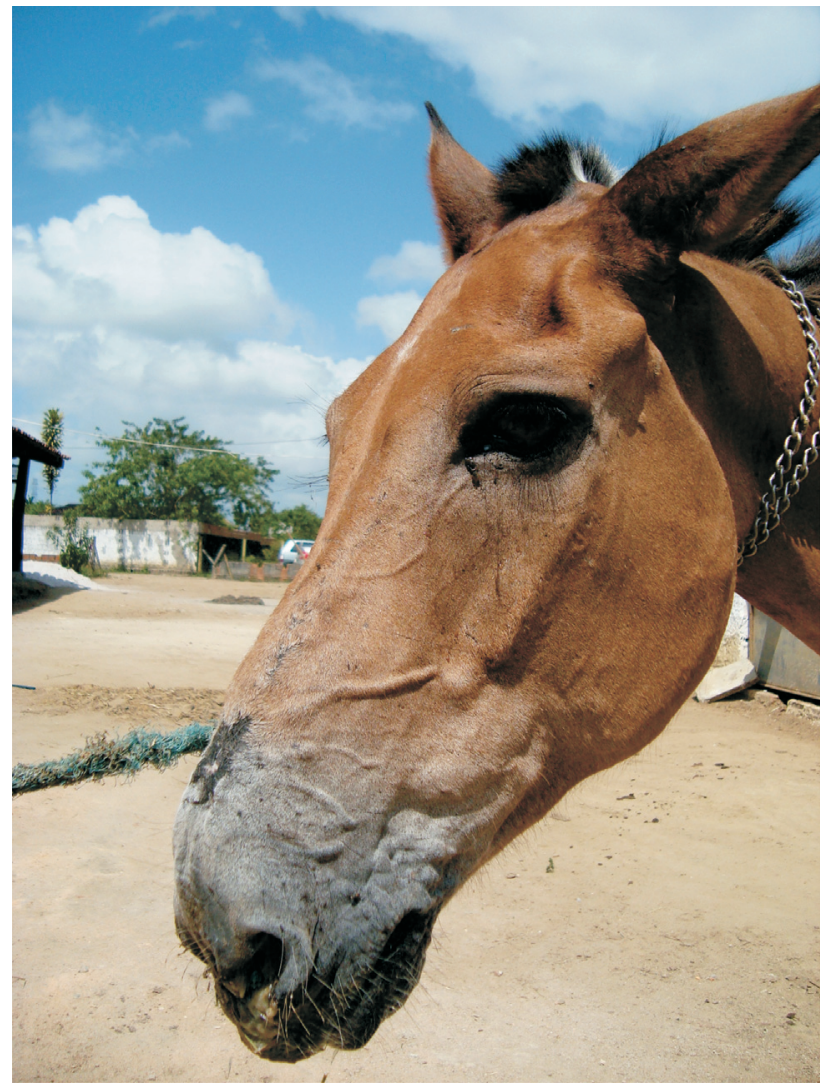

Figure 1 - Control group without inflammatory reaction or any other clinical signs were observed in the inoculated left eye.

cytokines such as IL-2 that reinforces the activation of Th-1 lymphocytes activated against $B$. mallei, thus enhancing DTH reactions (Amemiya et al., 2002).

Malleinization has greater specificity in the diagnosis of glanders as compared to other techniques, and its greater sensitivity should be considered for confirmation of positive cases as well as for clarification of doubts about the reaction of CF (Naureen et al., 2007). The test is inexpensive, easy to apply and commonly used in endemic areas for identifying horses carrying the infection after the completion of serology. The disadvantage is that the test may cause transient seroconversions in non-infected healthy animals as long as 45 days after the test. Thus, sera from negative tested animals become reagents in the CF (Huitema, 1969; Hagebock et al., 1993). Another limitation of the mallein test includes the negative results in horses in the disease's advanced stage due to the development of anergy due to peripheral immune tolerance (Verma et al., 1981; Jana et al., 1982).

A study conducted in healthy and infected horses found that the mullein test is perfectly reliable, even in cases when the disease is beginning (Naureen et al., 2008). With a positive predictive value of $92 \%$ in the acute and chronic phases of the disease and a negative predictive value of $96 \%$ in advanced cases, it is the most indicated test to clarify the suspected cases of glanders in the CF. Other tests, as agglutination reaction, hemagglutination inhibition 


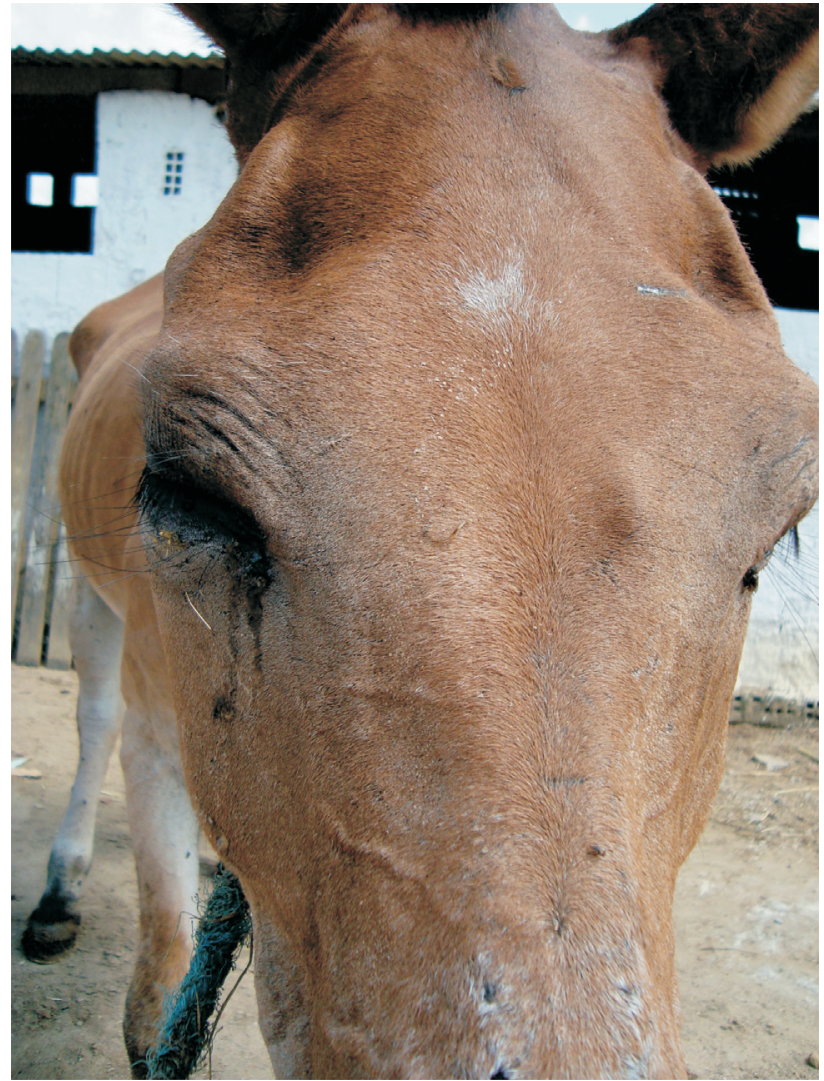

Figure 2 - Animal (Equus asinus) mallein-test reagent, progressive and persistent swelling right lower eyelid, with a peak $48 \mathrm{~h}$ after inoculation, ocular discharge was observed in some animals.

and immunoelectrophoresis are inferior in specificity and sensitivity as compared to the mallein test (Verma et al., 1994).

In this study, despite the small number of animals tested, the mullein produced was effective for identifying the true positive animals as well as those animals negative for glanders with $100 \%(5 / 5)$ of agreement among them, being a new possibility for the diagnosis and control of glanders in the country. However, it is necessary to apply this immunogen in a larger number of positive and negative animals in order to eliminate possible interpretation doubts in the diagnosis of this disease. Additionally, future prospects for standardization and validation of a quick serological test with high sensitivity applicable to routine diagnosis should be considered to reduce nonspecific reactions and increase the correlation between serological and mallein tests.

\section{Acknowledgments}

The authors wish to thank the National Council for Scientific and Technological Development (CNPq) and the Pernambuco State Foundation for Science and Technology (FACEPE) for financially supporting this research.

\section{References}

Amemiya K, Bush GV, Desahazer D, Waag DM (2002) Nonviable Burkholderia mallei induces a mixed Th1 and Th2 Like cytokine response in $\mathrm{BALB} / \mathrm{c}$ mice. Infect Immun 70:2319-2325.

Al-Ani FK, Al-Rawsashdeh OF, Ali HA, Hassan FK (1998) Glanders in horses: Clinical, biochemical and serological studies in Iraq. Vet Arhiv 68:155-162.

Brazil (2004) I.N. n. 24, de 5 de Abril de 2004. Normas para o Controle e a Erradicação do Mormo. Ministério da Agricultura, Pecuária e Abastecimento, Brasília, pp 274-278.

Hagebock JM, Schlater LK, Frerichs WM, Olson DP (1993) Serologic responses to the mallein test for glanders in solipeds. J Vet Diagn Invest 5:97-99.

Huitema H (1969) Production of mallein PPD. Neth J Vet Sci 2:127-133.

Jana AM, Gupta AK, Pandya G, Verma RD, Rao KM (1982) Rapid diagnosis of glanders in equines by counterimmuno-electrophoresis. Indian Vet J 59:5-9.

Mota RA, Brito MF, Castro FJC, Massa M (2000) Mormo em equídeos nos Estados de Pernambuco e Alagoas. Pesq Vet Bras 20:155-159.

Naureen A, Saqib M, Muhammad G, Hussain MH, Muhammad N (2007) Comparative evaluation of Rose Bengal plate agglutination test, mallein test, and some conventional serological tests for diagnosis of equine glanders. Asi J Vet Diagn Invest 19:362-367.

Naureen A, Saqib M, Asi MA, Hussain MH, Ghulam M (2008) On-site test for Equine Glanders. Equine Disease Quarterly 17:3-4.

Neubauer H, Sprague LD, Zacharia R, Tomaso H, Al Dahouk S, Wernery R, Wernery U, Scholz HC (2005) Serodiagnosis of Burkholderia mallei infections in horses. J Vet Med B Infect Dis Vet Public Health 52:201-205.

OIE, World Animal Health Organisation (2008) Manual of Diagnostic Tests and Vaccines for Terrestrial Animals. oie.int/eng/en_index.htm. 01-17. Accessed April 2, 2010.

Rabelo SSA, Soares PC, Mota RA (2006) Indicadores clínicos em muares naturalmente infectados pela Burkholderia mallei. Vet Zootec 13:54-62.

Silva KPC (2010) Produção e Avaliação da Proteína Derivada (PPD) de Burkholderia mallei para o Diagnóstico ImunoAlérgico do Mormo em Equídeos. Tese de Mestrado em Ciência Veterinária, Universidade Federal Rural de Pernambuco, $98 \mathrm{pp}$.

Verma RD (1981) Glanders in India with special reference if incidence and epidemiology. Indian Vet J 58:177-183.

Verma RD, Sharma JK, Venkateswaran KS, Batra HV (1990) Development of an Avidin-biotin dot enzyme-linked immunosorbent assay and its comparison with other serological tests for diagnosis of glanders in equines. Vet Microbiol 15:7785.

Verma RD, Venkateswaran KS, Sharma JK, Agarwal GS (1994) Potency of partially purified malleo-proteins for mallein test in the diagnosis of glanders in equines. Vet Microbiol 41:391-397.

All the content of the journal, except where otherwise noted, is licensed under a Creative Commons License CC BY-NC. 